\title{
INFLUENCIA DEL USO DE UN ENTORNO VIRTUAL EN EL RENDIMIENTO ACADÉMICO DE ESTUDIANTES DE ODONTOLOGÍA, CUSCO.
}

\author{
GALINDO V*, DE LA TORRE C. ${ }^{* *}$, VERA H. ${ }^{* * *}$ \\ * Maestra en Docencia Universitaria (UAC), Especialista en Radiología Oral y Maxilofacial (UPCH), \\ ID Orcid https://orcid.org/0000-0002-3811-6645 \\ ** Magister en Estadística (UNMSM), Doctor en Ciencias, Especialidad: Economía y Gestión (UNSA) \\ Docente de Universidad Nacional de San Antonio Abad del Cusco, Docente de la Escuela de Posgrado UAC. \\ *** Magister en Odontología (UPCH) Doctora en ciencias de la salud (UCSMA),Docente de pregrado de la \\ Universidad Andina del Cusco y Universidad Nacional San Antonio Abad del Cusco
}

\section{Resumen}

La plataforma virtual es una herramienta interactiva adaptada a la formación académica y empleada como complemento y apoyo a la tarea docente en la enseñanza. El objetivo de la investigación fue determinar la influencia de la plataforma Moodle en el rendimiento académico de la dimensión formativa de los estudiantes de la Escuela de Estomatología de la Universidad Andina del Cusco durante el año 2015. La población fue de 133 estudiantes de la asignatura de Radiología: 77 mujeres y 56 varones, el grupo control estuvo compuesto por 36 y el grupo experimental: 30 . Los resultados encontrados fueron que la influencia del uso del entorno virtual fue significativa en el segundo y tercer periodo académico. Se concluye que dicha influencia fue positiva con una eficiencia del $15 \%$ sobre el rendimiento académico de los estudiantes participantes.

\section{Abstract}

The virtual platform is a interactive tool adapted to the academic training and used as a complement and support to the teaching. The research objetive was to determine Moodle platform influence in the academic performance of the formative dimension of the students of the Stomatology School at the Universidad Andina del Cusco, during the year 2015. The population was 133 Radiology students: 77 women and 56 men, 36 from the control group and 36 from the experimental group. The results about the use influence of the virtual environment was significant in the second and third academic period. The conclution was positive influence with an efficiency of $15 \%$ on the academic performance of the participating students

\section{Introducción}

Dentro del contexto de la pandemia mundial de Covid-19, el status quo de la educación en general, se ha puesto en cuestión ${ }^{1}$. En cuanto al área de salud, los docentes deben afrontar el reto y aprovechar esta contingencia para adaptar sus métodos y técnicas a la virtualización. 
El uso de las nuevas Tecnologías de la Información y Comunicación (TICS) representan el cambio de paradigma tradicional de la educación superior a un nuevo enfoque centrado en el aprendizaje del estudiante, donde se debe otorgar mayor protagonismo y autonomía al mismo quedando el profesor obligado a "enseñar a aprender". 2

El Moodle es un acrónimo de Modular Object-Oriented Dynamic Learning Environment (Entorno modular de Aprendizaje Dinámico Orientado a Objetos), es un sistema de gestión de enseñanza basado en un software diseñado para ayudar a los educadores a crear entornos de aprendizaje virtuales, como afirma Dougiamas, su creador: "Internet cambia la forma como se educa". El uso de la plataforma virtual aporta beneficios al aprendiente y al docente, partiendo de la premisa de optar por una evaluación centrada en el proceso, pero con el doble objetivo de que los alumnos desarrollen su creatividad con una herramienta cómoda que se adapta a estas necesidades. ${ }^{3}$

Este sistema se sustenta en la teoría constructivista social de la pedagogía, por la que se afirma que el conocimiento se construye en la mente de los estudiantes, mediante la reflexión crítica y actividades. ${ }^{4}$

Las herramientas con las que cuenta este entorno son: tareas en línea, chat, foros, cuestionarios, consultas, etiquetas, páginas, recursos URL, eventos y otros que facilitan el trabajo del docente y su relación con el estudiante. ${ }^{5}$ (figura 1)

En este nuevo contexto de educación virtual ineludible para todos los niveles de preparación académica, presentamos una experiencia en educación universitaria con componente virtual y la influencia que tuvo en el rendimiento académico de los estudiantes de Radiología de la Escuela Profesional de Odontología.

\section{Materiales y Métodos}

La investigación tuvo un enfoque cuantitativo, de alcance explicativo, y diseño cuasi-experimental. La población considerada fueron 133 estudiantes matriculados en la asignatura de Radiología, correspondiente al cuarto semestre de la Escuela Profesional de Estomatología durante el año 2015, 77 mujeres y 56 varones. El tipo de muestreo fue no probabilístico por conveniencia, se consideró estudiantes que rindieron la evaluación de entrada, como criterio de inclusión. El grupo control estuvo compuesto por 36 estudiantes y el grupo experimental: 30 .

La técnica de recolección de datos fue una encuesta, el instrumento: un cuestionario de preguntas cerradas y abiertas que se aplicaron al finalizar cada periodo académico. Para validar el instrumento se aplicó el juicio de expertos, los cuales fueron dos doctores en educación, uno docente en el área de Educación y 
el segundo; docente en Ciencias de la Salud. Los mencionados ubicaron su opinión sobre la misma en el rango de: "muy bueno" y "excelente".

\section{Resultados}

\section{Rendimiento Académico Antes del Uso De Plataforma Moodle.}

Para constatar la homogeneidad entre el grupo control y experimental se observó el rendimiento académico de inicio, mediante una prueba de entrada, tomada de forma previa, en el primer contacto con ambos grupos.

\begin{tabular}{|c|c|c|c|c|c|}
\hline & $\begin{array}{l}\text { Prueba de } \\
\text { Entrada-Grupo } \\
\text { control }\end{array}$ & $\begin{array}{l}\text { Prueba de } \\
\text { Entrada- } \\
\text { Grupo } \\
\text { experimental }\end{array}$ & $\begin{array}{l}\text { Prueba de } \\
\text { normalidad }\end{array}$ & Prueba estadística & Resultado \\
\hline \multirow{2}{*}{$\begin{array}{l}\text { Recuento } \\
\text { Promedio } \\
\text { Desviación } \\
\text { Estándar }\end{array}$} & $\begin{array}{c}36 \\
7.38889\end{array}$ & $\begin{array}{c}30 \\
8.53333\end{array}$ & $\begin{array}{l}\text { Kolmogorov- } \\
\text { Smirnov } \\
\text { Valor }\end{array}$ & \multirow[t]{2}{*}{$\begin{array}{l}\text { Prueba } t=-1.41609 \\
\text { valor- } P=0.161599\end{array}$} & $\begin{array}{l}\text { El rendimiento académico } \\
\text { de los estudiantes del } \\
\text { grupo control }\end{array}$ \\
\hline & 3.34901 & 3.17026 & $P=0,421$ & & $\begin{array}{l}\text { experimental fue similar en } \\
\text { la prueba de entrada. }\end{array}$ \\
\hline
\end{tabular}

Tabla 1: Rendimiento académico de los estudiantes del grupo control y experimental en la prueba de entrada

De la prueba t-Student con $95 \%$ de confianza se encontró que los estudiantes que pertenecen al grupo control presentaron un rendimiento académico inicial promedio de 7.39 (desviación estándar de 3.34); y los estudiantes que pertenecían al grupo experimental presentaron un rendimiento promedio de 8.53 (desviación estándar de 3.17); lo que comprueba la homogeneidad de los grupos.

\section{Rendimiento académico posterior al uso de plataforma Moodle.}

\begin{tabular}{|c|c|c|c|c|c|}
\hline & $\begin{array}{l}\text { Promedio final - } \\
\text { Grupo Control }\end{array}$ & $\begin{array}{l}\text { Promedio final - } \\
\text { Grupo } \\
\text { Experimental }\end{array}$ & $\begin{array}{l}\text { Prueba de } \\
\text { normalidad }\end{array}$ & Prueba estadística & Resultado \\
\hline $\begin{array}{l}\text { Recuento } \\
\text { Promedio } \\
\text { Desviación } \\
\text { Estándar }\end{array}$ & $\begin{array}{c}36 \\
13.0833 \\
1.9328\end{array}$ & $\begin{array}{c}30 \\
15.0333 \\
2.28161\end{array}$ & $\begin{array}{l}\text { Kolmogorov- } \\
\text { Smirnov } \\
\text { Valor } \\
P=0,123\end{array}$ & $\begin{array}{l}\text { Prueba } t=- \\
3.75974 \text { valor- } \mathrm{P}= \\
0.000370708 \\
>0.05\end{array}$ & $\begin{array}{l}\text { El rendimiento académico de } \\
\text { los estudiantes del grupo } \\
\text { experimental fue superior al } \\
\text { del grupo control en el } \\
\text { promedio final }\end{array}$ \\
\hline
\end{tabular}

Tabla 2: Rendimiento académico de los estudiantes del grupo control y experimental en el promedio final.

El rendimiento académico en el promedio final de la asignatura de Radiologia en los estudiantes del grupo control fue de 13.08 con una desviación estándar de 1.93; mientras que en el grupo experimental obtuvieron un rendimiento académico promedio de 15.03 con una desviación estándar de 2.28, se puede observar que hubo un aumento significativo.

La eficiencia del entorno virtual en el rendimiento académico de los estudiantes de Radiología, fue el $15 \%$.

$$
\text { eficiencia }=\frac{\text { prom experim }- \text { prom control }}{\text { Prom control }} * 100 \%=\frac{15.03-13.083}{13.083} * 100 \%=14,88 \%
$$




\section{Rendimiento académico después del uso del entorno virtual, en cada uno de los periodos académicos.}

\section{Resultados del primer periodo académico.}

En este periodo el estudiante recibe contenidos introductorios y básicos de la material y se realiza la inducción al recurso virtual.

\begin{tabular}{|c|c|c|c|c|c|}
\hline & $\begin{array}{l}\text { Primer periodo } \\
\text { grupo control }\end{array}$ & $\begin{array}{l}\text { Primer periodo } \\
\text { grupo } \\
\text { experimental }\end{array}$ & $\begin{array}{l}\text { Prueba de } \\
\text { normalidad }\end{array}$ & Prueba estadística & Resultado \\
\hline $\begin{array}{l}\text { Recuento } \\
\text { Promedio } \\
\text { Desviación } \\
\text { Estándar }\end{array}$ & $\begin{array}{c}36 \\
13.25 \\
2.57876\end{array}$ & $\begin{array}{c}30 \\
13.7333 \\
2.86397\end{array}$ & $\begin{array}{l}\text { Kolmogorov- } \\
\text { Smirnov } \\
\text { Valor } \\
\mathrm{P}=0,187\end{array}$ & $\begin{array}{c}\mathrm{t}= \\
\text { valor- } \mathrm{P}=0.721013 \\
0.473527\end{array}$ & $\begin{array}{l}\text { No hubo diferencias } \\
\text { significativas en el } \\
\text { rendimiento académico de } \\
\text { los dos grupos. }\end{array}$ \\
\hline
\end{tabular}

Tabla 3: Rendimiento académico de los estudiantes del grupo control y experimental en el primer periodo académico

El rendimiento en el primer periodo académico fue similar para ambos grupos en el primer periodo académico, en el grupo control fue de 13,25 (desviación estándar de 2.58) y en el grupo experimental un promedio de 13,73 (desviación estándar de 2.86).

\section{Resultados del segundo periodo académico.}

En esta fase, el estudiante comienza a formar su capacidad de interpretación de imágenes anatómicas y patológicas.

\begin{tabular}{|c|c|c|c|c|c|}
\hline & $\begin{array}{l}\text { Segundo } \\
\text { periodo grupo } \\
\text { control }\end{array}$ & $\begin{array}{l}\text { Segundo periodo } \\
\text { grupo } \\
\text { experimental }\end{array}$ & $\begin{array}{l}\text { Prueba de } \\
\text { normalidad }\end{array}$ & Prueba estadística & Resultado \\
\hline $\begin{array}{l}\text { Recuento } \\
\text { Promedio } \\
\text { Desviación } \\
\text { Estándar }\end{array}$ & $\begin{array}{c}36 \\
14.3889 \\
2.84131\end{array}$ & $\begin{array}{c}30 \\
16.1 \\
2.44032\end{array}$ & $\begin{array}{l}\text { Kolmogorov- } \\
\text { Smirnov } \\
\text { Valor } \\
\mathrm{P}=0,371\end{array}$ & $\begin{array}{l}t=-2.59526 \\
\text { valor-P } \\
0.0117078\end{array}$ & $\begin{array}{l}\text { El rendimiento académico en } \\
\text { el segundo periodo fue } \\
\text { mayor en el grupo } \\
\text { experimental. }\end{array}$ \\
\hline
\end{tabular}

Tabla 4: Rendimiento académico de los estudiantes del grupo control y experimental en el segundo periodo académico.

El rendimiento académico promedio en el grupo control fue de 14,39 (desviación estándar de 2.84) y en el grupo experimental de 16.1 (desviación estándar de 2.44), estos resultados nos indican que en esta etapa si hubo una influencia positiva del uso del entorno virtual.

\section{Resultados del tercer periodo académico.}

Fase que consolida la formación del estudiante en sus capacidades interpretativas de imágenes maxilofaciales 


\begin{tabular}{|c|c|c|c|c|c|}
\hline & $\begin{array}{l}\text { Tercer periodo } \\
\text { Grupo control }\end{array}$ & $\begin{array}{l}\text { Tercer periodo } \\
\text { Grupo } \\
\text { experimental }\end{array}$ & $\begin{array}{l}\text { Prueba de } \\
\text { normalidad }\end{array}$ & Prueba estadística & Resultado \\
\hline $\begin{array}{l}\text { Recuento } \\
\text { Promedio } \\
\text { Desviación } \\
\text { Estándar }\end{array}$ & $\begin{array}{c}36 \\
11.1944 \\
2.55029\end{array}$ & $\begin{array}{c}30 \\
15.1667 \\
2.52003\end{array}$ & $\begin{array}{l}\text { Kolmogorov- } \\
\text { Smirnov } \\
\text { Valor } \\
P=0,234\end{array}$ & $\begin{array}{l}t=-6.33457 \text { valor- } \\
P=2.69173 E-8\end{array}$ & $\begin{array}{l}\text { El rendimiento académico en } \\
\text { el tercer periodo fue } \\
\text { significativamente mayor en } \\
\text { el grupo experimental. }\end{array}$ \\
\hline
\end{tabular}

Tabla 5: Rendimiento académico de los estudiantes del grupo control y experimental en el tercer periodo académico.

Observamos que el rendimiento académico fue significativamente mayor en los estudiantes que pertenecen al grupo experimental con un promedio de 15.17 (desviación estándar de 2.52), frente al rendimiento del grupo control que tuvo un promedio de 11.19 (desviación estándar de 2.55).

\section{Comparación del rendimiento académico en el Grupo Experimental antes y después del uso del entorno virtual.}

\begin{tabular}{|c|c|c|c|c|c|}
\hline & $\begin{array}{l}\text { Grupo } \\
\text { experimental- } \\
\text { Previa al uso del } \\
\text { entorno virtual }\end{array}$ & $\begin{array}{c}\text { Grupo } \\
\text { experimental- } \\
\text { Posterior al uso } \\
\text { del entorno virtual. }\end{array}$ & $\begin{array}{l}\text { Prueba de } \\
\text { normalidad }\end{array}$ & Prueba estadística & Resultado \\
\hline $\begin{array}{l}\text { Recuento } \\
\text { Promedio } \\
\text { Desviación } \\
\text { Estándar }\end{array}$ & $\begin{array}{c}30 \\
8.53333 \\
3.17026\end{array}$ & $\begin{array}{c}30 \\
15.0333 \\
2.28161\end{array}$ & $\begin{array}{l}\text { Kolmogorov- } \\
\text { Smirnov } \\
\text { Valor } \\
\mathrm{P}=0,175\end{array}$ & $\begin{array}{l}t=-9.11484 \text { valor }- \\
P=0.0\end{array}$ & $\begin{array}{l}\text { El rendimiento académico } \\
\text { del grupo experimental se } \\
\text { incrementó } \\
\text { significativamente respecto } \\
\text { a la evaluación inicial. }\end{array}$ \\
\hline
\end{tabular}

Tabla 6: Rendimiento académico de los estudiantes del grupo experimental antes y después del uso del entorno virtual.

El rendimiento académico del grupo experimental presenta un incremento importante respecto al momento previo y posterior de la implementación del entorno virtual. Antes del uso del entorno mostraron un rendimiento promedio de 8.53 (desviación estándar 3.17); después del uso del entorno; un promedio de 15.03 (desviación estándar de 2.28).

\section{Discusión}

Los resultados que encontramos fueron diferentes para los tres periodos académicos: en el primer periodo el uso del entorno virtual no mostró influencias significativas sobre el rendimiento académico. Los estudios de PEÑA en el 2006, en Colombia, al igual que nosotros no evidenciaron diferencias estadísticamente significativas en el nivel de aprendizaje en los grupos de estudio ${ }^{7}$. Podemos explicar este resultado debido a ser este periodo de naturaleza introductoria, en este momento la mayoría de estudiantes se encontraba en etapa de inducción en un sistema novedoso. También recalcar que en esta etapa se imparten conocimientos básicos y preliminares en cuanto a Radiológica, donde aún no se ejercita la interpretación de imágenes radiográficas propiamente dicha y en el cual se enfatiza en técnicas de toma de radiografías y principios físicos.

Para el segundo y tercer periodo académico, que corresponde a reconocimiento de estructuras anatómicas e interpretación de imágenes patológicas, se logra la 
competencia final de la asignatura, en las cuales se encontraron diferencias significativas favorables; en estas etapas los estudiantes son formados en criterios y sistemas de interpretación radiográfica para ello se utilizan mayor cantidad de herramientas virtuales interactivas como son: cuestionarios visuales en línea, foros, cuestionarios que utilizan el método del Caso y el Aprendizaje Basado en Problemas. Al respecto coincidimos con Lara y Los Ángeles, en Granada España ${ }^{2}$, quienes al encontrar resultados similares en cuanto a la complementación de la docencia presencial, donde el alumno adquirió otras destrezas de interpretación a través de las herramientas mostradas en la plataforma; concluyeron que la herramienta virtual abre la puerta a otras formas de aprendizaje de conocimientos y propicia una mayor interacción entre profesor-alumno a través de las tutorías virtuales; y entre alumno-alumno, a través de los debates.

El tercer periodo académico comprendió mayor actividad interpretativa, el estudiante debe alcanzar dicha capacidad y es donde obtuvimos los resultados más favorables con respecto a la virtualización. Citamos aquí a Ruiz ${ }^{8}$, quien realizó su investigación en la Universidad de San José de Costa Rica aplicando una estrategia digital para la enseñanza del curso de Interpretación Radiológica, con resultados favorables. Utilizó también el Método del Caso de manera virtual, de manera grupal, obteniendo resultados positivos en el aprendizaje de patología maxilofacial.

Por su parte Sendra $\mathrm{F}^{9}$ en su investigación sobre la enseñanza electrónica de Radiología en pregrado en la Universidad de Málaga-España, utilizó una presentación en diapositivas el programa Power Point con una serie de casos normales y patológicos; concluye considerando la simbiosis entre la clase virtual y la clase presencial adaptadas mutuamente es útil para aprovechar el tiempo de aprendizaje.

Torales en el Málaga- España, durante el 2008 diseñó una aplicación multimedia denominada AMERAN para el estudio de Radiología en la carrera de Medicina; concluye que el sistema es factible técnicamente, se puede manejar contenidos virtuales sin detrimento en la formación académica del alumno ${ }^{8}$. Nos interesa la similitud de la asignatura que ellos tomaron y como al igual que nosotros encuentras resultados positivos, remarcando aquí, que ambos utilizamos las herramientas virtuales como complementos a la docencia presencial.

En cuanto al análisis de la influencia del uso del entorno virtual en el rendimiento académico de los estudiantes de grupo experimental fue positivo. En nuestro ámbito de estudio, específicamente en la misma universidad, Salazar ${ }^{11}$ en el 2014, realizó un estudio en estudiantes de la escuela profesional de Derecho, midiendo la influencia del cine como estrategia didáctica en el curso de Razonamiento Jurídico, utilizando tambien como parámetro el rendimiento académico de dos grupos similares de estudiantes; encontrando resultados positivos; al igual que 
nuestra investigación. En otra investigación peruana del 2013, realizada por Aguilar $^{12}$ sobre cómo influye el uso de las aulas virtuales en el aprendizaje de los estudiantes del curso de Internado Estomatológico en una Universidad de San Martin de Porres - Lima, observaron que el uso de las aulas virtuales tiene una influencia significativa en el aprendizaje.

En el marco de la contingencia producida por la pandemia del Covid-19, debemos reconocer que los recursos tecnológicos como son los entornos virtuales y otros comentados, nos dan la oportunidad de reinventar la educación superior y adaptarla a la condición no presencial que exige el momento actual, sin perjuicio de su calidad, ya que como hemos observado, dichas herramientas ofrecen evidencias de ser altamente eficientes en la mejora del rendimiento académico.

\section{Conclusión}

El uso del entorno virtual Moodle influenció positivamente el rendimiento académico de los estudiantes participantes, con un incremento del $15 \%$, siendo esta influencia positiva en el segundo y tercer periodo de estudio. Cabe mencionar que dicha herramienta se utilizó como complemento de la docencia presencial; dando así apertura a la interrogante sobre la eficiencia de estos entornos en la docencia virtual en su totalidad.

\section{Referencias Bibliográficas}

1. Costa MJ, Carvalho-Filho M. Una nueva época para la educación médica después de la COVID-19. Rev Fund Educ Médica. 2020;23(2):55.

2. Lara M. y Los Angeles M.. La Plataforma Virtual Webct como complemento de la Docencia Presencial en la Asignatura Procesos Y Productos Biotecnologicos. Actas de las I Jornadas sobre Innovación Docente y Adaptación al EEES, 2010; 171-174.

3. Rodríguez A. S. El uso de la plataforma virtual en la evaluación continua. Vieira. (2010).

4. Entornos Educativos. 2013. Recuperado el 14 de setiembre de 2015. Disponible en: http://www.entornos.com.ar/contacto.

5. Benavides, J. Administración de base de datos y Plataforma Virtual. Entrevista reaizada el 10 de enero de 2014.., Entrevistador Galindo V.

6. Cosano F. La Plataforma Moddle como como instrumento para el trabajo social en el contexto del Espacio Europeo de Educación Superior. Universidad de Malaga. 2010.

7. Peña M. Evaluación de la Implementación del Aula Virtual en la Instiución de Educación Superior. 2006

8. Ruiz A. Aplicación de una Estrategia Didáctica en el Curso De Interpretación Radiológica Para Estudiantes de Odontología: uso del método del caso y trabajo grupal. Revista de la Facultad de Estomatologia, Universidad Nacional de Costa Rica, 2010,; 24-28.

9. Sendra F. Enseñanza electrónica de radiología en pregrado: la experiencia de la universidad. Red de Revistas Científicas de América Latina, el Caribe, España y Portugal, 2010; 116-145. 
10. Torales O. Diseño y Evaluacion de una aplicación multimedia para la enseñanza de radiologia a alumnos de medicina (ameram). Malaga, España. 2008

11. Salazar A. El Cine como estrategia Metodológica en el curso de Razonamiento Jurídico. Cusco, Perú: Universidad Andina del Cusco, 2014.

12. Aguilar M. Influenci de las aulas virtuales en el aprendizaje por competencias de los estudiantes del Internado Estomatoógico de la Facultd de Estomatología de la Universiddad San Martin de Porres, 2013. Lima, Peru, 2013. 